\title{
Datos abiertos culturales y desarrollo socioeconómico
}

Sergio Reyes-Corredera | grupo de investigación HUM-776 Análisis Geográfico, Dpto. de Geografía, Universidad de Málaga

URL de la contribución <www.iaph.es/revistaph/index.php/revistaph/article/view/3965>

Cíclicamente en los medios aparece esa conocida comparativa de la evolución de las unidades de medida del valor económico y se suele indicar -no es novedad-, que la obtención, gestión y tratamiento de los datos serán el nuevo petróleo. Investigando rápidamente en el buscador más conocido de la red se puede observar cómo las noticias relacionadas con este asunto ya disponen de entradas años atrás ${ }^{1}$. Merece la pena reflexionar si la explotación de estos datos es una oportunidad económica en igualdad de condiciones para cualquier usuario y si su transferencia o utilidad a la sociedad es óptima o bien puede ser mejorable.

Esta reflexión, en el marco de los datos culturales, hace prestar especial atención a la pequeña y mediana empresa y, en particular, al subconjunto de los empresarios y empresarias emprendedores. Debido a la complejidad de acceso a información en el marco de su área trabajo (la cultura) y a las dificultades que pueden tener en el momento de estudiar su idea de negocio en el mercado, en muchas ocasiones se produce un fracaso temprano, incluso teniendo un componente innovador, debido a complicaciones de explotación al no conocer cuestiones relativas al perfil del consumidor del bien o servicio, la competencia empresarial con la que se pueden encontrar, etcétera.

A la cuestión anterior hay que sumarle la geolocalización de estos datos, una variable más que puede ayudar a conocer nichos de mercado culturales no puestos en valor o conocer cuáles son los espacios en los que hay una ardua actividad cultural. Desde el punto de vista de la Administración, la disponibilidad de estos datos geográficos también puede tener un uso en el ámbito de la gestión cultural y patrimonial. El más claro ejemplo se sitúa en la gestión de la capacidad de carga de los bienes culturales evitando la saturación de espacios turísticos.
Los datos abiertos también son un gran incentivo para la participación ciudadana siempre que vengan acompañados de una buena accesibilidad a las herramientas electrónicas y una facilidad de uso. El empleo y desarrollo de aplicaciones para smartphone o la creación de visores o geoportales pueden ser una buena fuente para conocer las experiencias de los usuarios; sus valoraciones sobre el bienestar o malestar de las actividades económicas ligadas al mundo de la cultura mediante la generación de bases de datos normalizadas para poder recabar estadísticas y conocer las tendencias del público, para corregir carencias sobre la experiencia en un espacio cultural, así como conocer propuestas desde el punto de vista del usuario. Para llevar a cabo esta tarea habrá que aplicar el marco normativo vigente en lo referido a protección de datos, salvaguarda del anonimato así como no vulnerar el secreto estadístico. El resultado de esta síntesis estadística y de tendencias así como su libre acceso puede llegar a ser una excelente oportunidad de conocimiento del perfil usuario de un espacio cultural por el cual un emprendedor puede disponer de información sin tener que acabar por externalizar un servicio del que, en muchas ocasiones, no dispone del capital suficiente para contratarlo.

De todo lo anteriormente expuesto se puede deducir que los datos que deben ser ofertados en abierto harán referencia al volumen de visitantes de los espacios y eventos culturales, sus perfiles socioeconómicos, el lugar de procedencia, el interés que les hace asistir a un acto, evento o ruta cultural, entre otros parámetros. Este conglomerado de información asociado a la oferta cultural de empresas que presenten servicios del tipo free tours, servicios gastronómicos o cualquier tipo de oferta cultural complementaria con características privadas puede verse beneficiada por la disponibilidad de estos datos e, incluso, para aquellas que quieren implantarse en una localidad conociendo el registro de la oferta privada exis- 


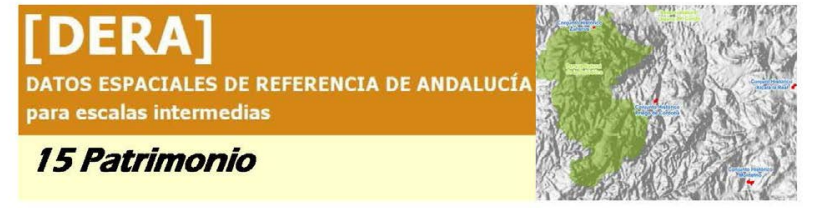

Resumen: Este conjunto de datos espaciales está conformado por doce capas de información geográfica alusivas a diferentes elementos referidos tanto al patrimonio histórico como al natural (bienes de interés cultural, cavidades, espacios naturales protegidos, geoparques, etc) existente en la Comunidad Autónoma de Andalucía.

Datos espaciales de referencia en Andalucía (https://www.ieca.junta-andalucia. es/DERA/g15.htm)

tente ligada a cada espacio cultural para conocer la oportunidad de negocio de la que dispone, desechando de este modo aquellos espacios con una intensa actividad económica y acercándose a otros que puedan ofrecer nuevas oportunidades, ligándolas con otras potencialidades culturales o no culturales de un mismo espacio. De esta manera se puede dar un importante margen de implantación al emprendimiento y a la innovación empresarial en el ámbito cultural².

El caso de Andalucía en relación con las experiencias de la gestión del patrimonio cultural a través de datos abiertos es ciertamente paradigmático ya que se dispone de una amplia red de datos abiertos tanto a nivel municipal (en grandes ciudades y en algunas medianas) y a escala regional donde existen datos culturales geolocalizados de libre acceso en el Instituto de Estadística y Cartografía de Andalucía (IECA) a través de su producto DERA, cada vez más amplio y variado.

Una sinergia entre las entidades encargadas de gestionar los programas y políticas culturales de nuestra región y el IECA puede ser un gran e importante paso que facilite, a toda la Administración Pública, en sus diferentes escalas, una óptima y completa gestión de los bienes culturales y patrimoniales. El desarrollo de estos datos facilitará tanto a las empresas vigentes como a las que puedan surgir en el futuro la capacidad de realizar mejores y más completos estudios de mercado, análisis de viabilidad de productos, etc. La gran mayoría de estos datos proven- drán directamente de la información de todos los entes culturales de nuestra región (museos, rutas culturales, espectáculos, etc.). Otros tendrán su origen en la información de los sectores que se alimentan de la actividad cultural como pueden ser los alojamientos, los cuales emiten datos sobre los perfiles de los visitantes a instituciones como el Instituto Nacional de Estadística en su Encuesta de Ocupación en Alojamientos Turísticos a través de la aplicación ARCE (Almacenamiento y Recogida de Cuestionarios Económicos) o a través de la síntesis de resultados de las hojas-registro de la comunicación de datos a las dependencia policiales obligatoria para los establecimientos de hospedaje.

\section{NOTAS}

1. Búsqueda en Google de entradas acerca de "los datos serán el nuevo petróleo". Se recomienda revisar las fechas de las entradas.

2. Muestro mi agradecimiento a Alejandro Prieto de la empresa de tours y visitas turísticas Explora Málaga S.L. por el tiempo que dedicó a mis consultas sobre las mejoras que podría percibir su área de trabajo en relación con los datos abiertos culturales.

\section{BIBLIGRAFÍA}

- DERA (2017) Datos Espaciales de Referencia de Andalucía. Instituto de Estadística y Cartografía de Andalucía. Consejería de Economía y Conocimiento. Junta de Andalucía. <http:// www.juntadeandalucia.es/institutodeestadisticaycartografia/ DERA> [Consulta: 19/7/2017]

- INE(2017) Instituto Nacional de Estadística. Almacenamiento y Recogida de Cuestionarios Económicos <https://arce.ine.es/ ARCE/jsp/index.jsp> [Consulta: 12/7/2017]

- MINISTERIO del Interior (2017) Gobierno de España. Comunciación de datos a las dependencias policiales <http:// www.interior.gob.es/web/servicios-al-ciudadano/seguridad/ libro-registro-de-viajeros/comunicacion-de-datos-a-las-depen dencias-policial> [Consulta: 12/7/2017] 